\title{
Temporal and Spatial Variation in the Diet of the Endemic Lizard Gallotia galloti in an Insular Mediterranean Scrubland
}

\author{
Airam Rodríguez, ${ }^{1,2}$ Manuel Nogales, ${ }^{1}$ Beatriz Rumeu, ${ }^{1}$ and Beneharo Rodríguez ${ }^{3}$ \\ ${ }^{1}$ Island Ecology and Evolution Research Group (IPNA-CSIC), 38206 La Laguna, Tenerife, Canary Islands, Spain \\ ${ }^{3} \mathrm{C} /$ La Malecita S/N, 38480 Buenavista del Norte, Tenerife, Canary Islands, Spain
}

\begin{abstract}
Aвstract.-We analyzed 621 lizard fecal pellets to assess the diet of the endemic lizard Gallotia galloti (Lacertidae) throughout one year in the thermophilous scrubland, the most threatened habitat in the Canary Islands. Indicating the importance of frugivory, $98.1 \%$ of pellets contained seeds from fleshy-fruited plant species $(8,028$ seeds in total), and the fruit volume reached $47.5 \%$. The Canarian endemic plants Rhamnus crenulata and Canarina canariensis were most important in frequency of occurrence and number of seeds found in pellets, respectively. Lizards were more frugivorous during the summer (63.0\% of volume), and seasonal variation was associated with temporal changes in availability of ripe fleshy fruits. We detected microspatial differences in the consumption of fruits and plant material. Significant correlations were found between plant cover of each species and their respective consumption by lizards. Lizards consumed invertebrates throughout the year; Formicidae, Hemiptera, Coleoptera, and Hymenoptera were the most frequently consumed prey ( $76.5 \%$ of the animal prey items). Our results indicate that G. galloti is one of the most frugivorous lacertids studied. The high number of undamaged seeds removed by these lizards also implies an important role in the seed dispersal processes of many fleshy-fruited plant species from this threatened habitat.
\end{abstract}

Island biotas are unusual in many ways, including the tendency to have relatively broad trophic niches (Gorman, 1979). Therefore, one of the main tendencies of lizards in insular habitats, compared to mainland areas, is to include abundant plant matter in their diets (Pérez-Mellado and Corti, 1993; Van Damme, 1999; Cooper and Vitt, 2002; Olesen and Valido, 2003). High densities of lizards (Bennett and Gorman, 1979; Schoener and Schoener, 1980; Rodda and Dean-Bradley, 2002), lower arthropod prey availability (Janzen, 1973), larger body size (Szarski, 1962; Sokol, 1967; Pough, 1973; Herrel et al., 2004), lower predation risk (Szarski, 1962; Pérez-Mellado and Corti, 1993; Olesen and Valido, 2003), aridity, and foraging mode (Cooper and Vitt, 2002) has been suggested as the explanation of increase in plant material consumption on islands. However, Espinoza et al. (2004) demonstrated that most herbivorous liolaemids are small bodied and live in cool climates. Such patterns have not been examined in others lizards (e.g., the lacertids); therefore, many paths seem to lead to herbivory in lizards (Vitt, 2004).

In the case of Lacertidae, there appears to be a link between insularity and herbivory, although

\footnotetext{
${ }^{2}$ Corresponding Author. Present address: Estación Biológica de Doñana (CSIC), Pabellón del Perú, Avda. María Luisa S/N, 41013 Seville, Spain; E-mail: airamrguez@ipna.csic.es
}

the causes of this pattern have not been clarified (see Van Damme, 1999). The endemic genus Gallotia from the Canary Islands has an omnivorous diet, with abundant plant intake. The majority of plant material is made up of fruits (Valido, 1999; Valido and Nogales, 2003; Valido et al., 2003; Martín et al., 2005), which are temporarily available and present high levels of easily digestible sugars for frugivores (Jordano, 2000).

Gallotia galloti is a medium-sized lizard (maximum SVL: $145 \mathrm{~mm}$ ) that inhabits all Tenerife and La Palma ecosystems, being more abundant in open habitats. Its diet has been mainly studied in short-term projects (Díaz, 1980; Valido and Nogales, 1994, 2003; Roca et al., 2005). The only long-term study (annual) was performed in a xeric scrubland, characteristic of the Canarian lowlands (Valido et al., 2003). Diets often show intra- and interpopulation variation possibly related with resource availability; thus, short-term studies can miss important patterns (Valido and Nogales, 2003; Valido et al., 2003).

The flora of the thermophilous scrubland is made up of plants of Mediterranean origin (Sunding, 1979). This scrubland is highly diverse, and it harbors more than 20 fleshy-fruited plant species. In the Macaronesian Islands, scrubland was present in the Cape Verde, Madeira, and Canary Islands archipelagos. However, this habitat is currently restricted to the Canary Islands (González et al., 1986), 
TABle 1. Percentage of cover and mean number of seeds/fruit (MNS \pm deviation standard) of fleshy-fruited plant species present in El Pleito (Buenavista del Norte, Tenerife). Family, numbers of fruits studied $(N)$ and biogeography range are shown. EC: Canarian endemism, EM: Macaronesian endemism, NA: Native, NN: Nonnative, \#: values lower than $0.1 \%$. *: Data obtained from Nogales et al., 1999. Nomenclature of plant species follows the list of Izquierdo et al., 2004.

\begin{tabular}{|c|c|c|c|c|c|}
\hline Species & Family & $\begin{array}{c}\% \text { Plant } \\
\text { cover }\end{array}$ & $\mathrm{MNS} \pm \mathrm{SD}$ & $N$ & Biogeography range \\
\hline Jasminum odoratissimum & Oleaceae & 21.8 & $1.7 \pm 0.5$ & 80 & EM \\
\hline Rubia fruticosa & Rubiaceae & 16.5 & $1.2 \pm 0.4$ & 131 & EM \\
\hline Rhamnus crenulata & Rhamnaceae & 14.4 & $3.0 \pm 0.6$ & 189 & $\mathrm{EC}$ \\
\hline Pistacia atlantica & Anacardiaceae & 7.7 & $1 \pm 0$ & 32 & NA \\
\hline Heberdenia excelsa & Myrsinaceae & 7.6 & $1 \pm 0$ & 50 & EM \\
\hline Opuntia maxima* & Cactaceae & 6.7 & 184.2 & 5 & NN \\
\hline Rubus ulmifolius & Rosaceae & 3.6 & $19.8 \pm 12.7$ & 25 & NA \\
\hline Prunus dulcis & Rosaceae & 3.2 & $1 \pm 0$ & 5 & NN \\
\hline Canarina canariensis & Campanulaceae & 2.6 & $337.5 \pm 158.7$ & 8 & $\mathrm{EC}$ \\
\hline Tamus edulis & Dioscoreaceae & 1.4 & $3.5 \pm 2.0$ & 126 & EM \\
\hline Asparagus plocamoides & Convallariaceae & 1.3 & $0.9 \pm 0.4$ & 199 & EC \\
\hline Withania aristata & Solanaceae & 1.0 & $11.5 \pm 4.9$ & 102 & NA \\
\hline Bosea yervamora & Amaranthaceae & 0.5 & $1 \pm 0$ & 81 & EC \\
\hline Ruta pinnata & Rutaceae & 0.5 & $3.9 \pm 2.4$ & 230 & $\mathrm{EC}$ \\
\hline Osyris lanceolata & Santalaceae & 0.3 & $1 \pm 0$ & 30 & NA \\
\hline Asparagus umbellatus & Convallariaceae & 0.2 & $1.1 \pm 0.5$ & 26 & EM \\
\hline Bryonia verrucosa & Cucurbitaceae & 0.1 & $14.9 \pm 8.4$ & 7 & $\mathrm{EC}$ \\
\hline Scilla haemorrhoidalis & Hyacinthaceae & 0.1 & $3.7 \pm 1.7$ & 43 & $\mathrm{EC}$ \\
\hline Ficus carica* & Moraceae & $\#$ & 243.6 & 15 & NN \\
\hline Vitis vinifera & Vitaceae & $\#$ & $2.2 \pm 0.7$ & 15 & NN \\
\hline
\end{tabular}

where only a few fragments are still wellconserved, this being the most degraded and threatened of regional habitats (Santos, 2000).

The main aim of this study was to assess the role of fruits in the diet of lizards in a Mediterranean ecosystem under insular conditions. Therefore, we specifically tried to address the following objectives: (1) to describe in detail the seasonal diet of G. galloti in an insular Mediterranean scrubland; (2) to quantify the contribution of fruits in the diet and its relationship with fruit availability; (3) to assess the spatial pattern of fruit consumption related with the fleshy-fruited plant species distribution; (4) to compare its frugivorous diet with conspecifics inhabiting another Canarian xeric habitat (the coastal scrubland), where fleshyfruited plants are less diverse; and (5) to evaluate the frugivorous components of its diet with regards to lacertids on other islands.

\section{Materials And Methods}

Study Site.-Fieldwork was carried out from February 2005 to February 2006 in Buenavista del Norte (El Pleito, Northwest of Tenerife, Canary Islands $27^{\circ} 37^{\prime}-29^{\circ} 25^{\prime} \mathrm{N}$ and $13^{\circ} 20^{\prime}-$ $18^{\circ} 19^{\prime} \mathrm{W}$ ), which is one of the oldest geological sectors of the island (4.5-6.7 MYA, Ancochea et al., 1990). The climate is dry Mediterranean, with an annual temperature ranging between 16 and $19^{\circ} \mathrm{C}$ and a mean annual rainfall varying between 200 and $400 \mathrm{~mm}$, falling mainly between November and February. April through September is the driest period of the year (Marzol, 2000). The study site (200 m a.s.l.) is within one of the most biodiverse and better conserved thermophilous scrubland fragments (Santos, 2000). The north-facing slope is influenced by dominant humid winds from the Northeast year-round. In winter, because of this orientation, it receives little direct sunlight and is shaded most of the time.

Vegetation consists of shrubs with sparse tree cover and is dominated by Jasminum odoratissimum; Rhamnus crenulata, Hypericum canariense, Pistacia atlantica, and Heberdenia excelsa are also common. At least 23 Canarian endemic plant species and 20 fleshy-fruited plant species have been found in the study area (Table 1).

Diet Analysis. - We selected one linear transect of $500 \mathrm{~m}$ in length and $1 \mathrm{~m}$ wide, which was divided up into 10 subtransects each $50 \mathrm{~m}$ in length. This transect crossed the main types of vegetation present in the study area. Along each subtransect, we collected individual fecal pellets of G. galloti. To minimize pseudoreplication, no more than five lizard pellets were collected at the same site $\left(0.25 \mathrm{~m}^{2}\right)$. Prior to the first collection, we removed all fecal pellets present along the transect, to ensure that only recent pellets would be collected in subsequent surveys. We tried to find at least 200 pellets per season along the transect (Spring: March, April, 
and May; Summer: June, July, and August; Autumn: September, October, and November; Winter: December, January, and February), but in winter, it was impossible because lizards were less active. The diameter and length of each pellet was measured using a digital caliper (precision: $0.01 \mathrm{~mm}$ ). Because there was a correlation between pellet diameter and lizard size $\left(r_{p}=0.79 ; P=0.036\right.$; Valido and Nogales, 2003), we used this variable as a predictor of lizard body size. Pellets were air dried and dissected in Petri dishes. Plant and animal components were identified under magnification $(8-50 X)$. Seeds were identified to species level using the reference collection of the IPNACSIC, as well as seeds collected from plants in the field, whereas invertebrates were identified to order (except the Formicidae).

The results are expressed in three ways: (1) frequency of occurrence (\%) of each component (FO); (2) percentage of seeds of fleshy fruits or animal items in relation to the total number of these two items counted $(\% \mathrm{~N})$; and (3) percentage of volume $(\mathrm{V})$, roughly estimated to the nearest $10 \%$ in each pellet, for fleshy fruit, other plant material, invertebrate items, and other remains (vertebrates, stones, soil, etc.).

Seasonal Availability of Fruits and Vegetation Structure.-During the study year, we counted the total number of fruits on 10 branches for about 10 plants of each fleshy-fruited plant species present in the study area. For each of these randomly selected branches and plants, we made a monthly follow-up to obtain data on the number of green, ripe, and dry fruits, during the year. To study vegetation cover, we made five linear and perpendicular transects of $10 \mathrm{~m}$ distributed uniformly inside of each subtransect of $50 \mathrm{~m}$ (along the main transect) and recorded the percent cover for each plant species. For diocious species, we only report cover of female individuals.

Index Analysis.-Diet similarity or overlap among the different seasons was evaluated using the Morisita index for percentage of prey, in which values near " 0 " indicate low similarity and values near " 1 ," a high similarity (Krebs, 1999). Moreover, niche-breadth was assessed using the standardized Levin's niche-breadth index, where values close to " 0 " indicate a specialized diet and values close to "1," a generalized diet (Krebs, 1999). To calculate the index values, we used taxonomical levels showed in Table 2 . In the case of fruits with more than one seed per fruit, to quantify the number of consumed fruits, numbers of seeds were divided between mean numbers of seeds per fruit (see Table 1).

Statistical Analysis.-Temporal variation of volume $(\%)$ of invertebrates, fruit remains, and plant matter in diet (angular transformation) was analyzed using ANCOVA (fecal pellet diameter was considered as covariate, logarithmically transformed). To test possible significant differences in diet or pellets characteristics among seasons or subtransects, Kruskal-Wallis tests were used. We compared the main invertebrate groups consumed between seasons, with respect to the rest of prey, by applying likelihood-ratio tests. In those cases where it was necessary to reuse the same data set, this statistical effect was reduced by applying the more conservative sequential Bonferroni method for assessing statistical significance. We drew correlations between the percentage of the cover of each fleshy-fruited plant species and their respective consumption by lizards. Statistical calculations were carried out using SPSS (version 14.0; SPSS Inc., Chicago, IL).

\section{RESUlts}

Six hundred twenty-one pellets were analyzed. A total of 3,163 animal prey and 8,202 seeds was counted; at least $8,028(97.9 \%)$ of these seeds belonged to fleshy fruits (Table 2). Plant material reached $72.4 \%$ of V, $24.9 \%$ corresponded to leaves, flowers, and little stems and $47.5 \%$ to fruits (Fig. 1). Seeds of R. crenulata were the most frequent (FO) in the whole diet, whereas Canarina canariensis reached the highest value with regard to the total seeds found $(\% \mathrm{~N})$. Invertebrates constituted $25.7 \%$ of $\mathrm{V}$ in the general diet (Fig. 1). Ants, Hemiptera, Coleoptera, and Hymenoptera were the most consumed and frequent animal prey throughout the entire year, constituting $76.5 \%$ of animal prey $(\% \mathrm{~N})$. Three vertebrate species were documented; the presence of a G. galloti pelvis indicating cannibalism.

Temporal Variation of Diet.-Lizards were omnivorous throughout the year. Pellet diameters varied significantly among all seasons (Kruskal-Wallis test: $\chi_{3}^{2}=71.35, P<0.001$ subsequent $U$-tests, $P<0.003$ for all comparisons; Table 3). For the entire year, significant correlations were recorded between fecal pellet diameter and volume (\%) of invertebrate remains (Spearman correlation: $r_{s}=-0.31, P<$ $0.001)$, fruit remains $\left(r_{s}=0.26, P<0.001\right)$, and plant material $\left(r_{s}=0.37, P<0.001\right)$. Except for winter fecal pellets, which showed no significant correlations between these variables, the same pattern was recorded for the rest of the seasons $\left(r_{s}\right.$ ranging from -0.29 to 0.30 ; All $P<$ 0.02). Considering all pellet diameter (logtransformed) as a covariate to control for the possible effect of lizard size, significant seasonal variations were found between the volumes $(\%)$ 
TABLE 2 Composition of lizard (Gallotia galloti) diet during the year (March 2005 to February 2006) in El Pleito (Tenerife). FO: frequency of occurrence (percentage of droppings with the taxon present), and \%N: percentage of the total fruits or animals counted in droppings. $r_{s}$ : indicates the Spearman correlation between the parameters $\mathrm{FO}$ and $\% \mathrm{~N}$. The highest values of each component/season appear in bold face. ${ }^{* * *} P<0.001$. \# indicates values lower than $0.1 \%$.

\begin{tabular}{|c|c|c|c|c|c|c|c|c|c|c|}
\hline \multirow[b]{2}{*}{ Items } & \multicolumn{2}{|c|}{$\begin{array}{c}\text { Spring } \\
(N=200)\end{array}$} & \multicolumn{2}{|c|}{$\begin{array}{r}\text { Summer } \\
(N=200)\end{array}$} & \multicolumn{2}{|c|}{$\begin{array}{r}\text { Autumn } \\
(N=200)\end{array}$} & \multicolumn{2}{|c|}{$\begin{array}{r}\text { Winter } \\
(N=21)\end{array}$} & \multicolumn{2}{|c|}{$\begin{array}{c}\text { Total } \\
(N=621)\end{array}$} \\
\hline & $\mathrm{FO}$ & $\% \mathrm{~N}$ & $\mathrm{FO}$ & $\% \mathrm{~N}$ & $\mathrm{FO}$ & $\% \mathrm{~N}$ & $\mathrm{FO}$ & $\% \mathrm{~N}$ & $\mathrm{FO}$ & $\% \mathrm{~N}$ \\
\hline \multicolumn{11}{|l|}{ Fruit components } \\
\hline \multicolumn{11}{|l|}{ Fleshy fruits } \\
\hline $\begin{array}{l}\text { Canarina } \\
\quad \text { canariensis }\end{array}$ & 33.0 & 66.6 & 28.5 & 48.9 & 1.5 & 0.3 & - & - & 20.3 & 49.2 \\
\hline Rubia fruticosa & 59.0 & 24.2 & 13.0 & 4.3 & - & - & - & - & 23.2 & 12.0 \\
\hline Ficus carica & 1.0 & 0.1 & 21.0 & 11.0 & 27.5 & 36.3 & 14.3 & 10.3 & 16.4 & 10.0 \\
\hline Ruta pinnata & 3.0 & 1.5 & 24.5 & 11.5 & 19.0 & 16.1 & 9.5 & 6.9 & 15.3 & 7.9 \\
\hline Rhamnus crenulata & 3.5 & 0.4 & 49.5 & 7.7 & 54.5 & 21.2 & 23.8 & 20.7 & 35.4 & 6.6 \\
\hline $\begin{array}{l}\text { Jasminum } \\
\text { odoratissimum }\end{array}$ & 17.0 & 1.7 & 38.5 & 6.0 & 11.0 & 3.2 & 4.8 & 6.9 & 21.6 & 3.8 \\
\hline Rubus ulmifolius & - & - & 13.5 & 5.2 & 4.0 & 3.3 & 14.3 & 41.4 & 6.1 & 2.9 \\
\hline Opuntia maxima & 1.0 & 0.1 & 0.5 & \# & 22.5 & 12.9 & - & - & 7.7 & 1.9 \\
\hline Withania aristata & 5.5 & 2.5 & 4.0 & 0.5 & 0.5 & 0.3 & - & - & 3.2 & 1.3 \\
\hline Heberdenia excelsa & 1.5 & 0.1 & 9.5 & 0.7 & 8.5 & 2.3 & 4.8 & 3.4 & 6.4 & 0.7 \\
\hline Tamus edulis & 2.5 & 0.5 & 3.0 & 1.0 & - & - & - & - & 1.8 & 0.6 \\
\hline $\begin{array}{l}\text { Asparagus } \\
\text { poclamoides }\end{array}$ & 1.0 & 0.1 & 2.5 & 0.2 & 4.0 & 1.2 & - & - & 2.4 & 0.3 \\
\hline $\begin{array}{l}\text { Scilla } \\
\quad \text { haemorrhoidalis }\end{array}$ & 1.5 & 0.4 & 0.5 & 0.3 & - & - & - & - & 0.6 & 0.3 \\
\hline Vitis vinifera & - & - & 2.5 & 0.3 & 2.0 & 0.5 & - & - & 1.4 & 0.2 \\
\hline Bosea yervamora & 0.5 & \# & - & - & - & - & - & - & 0.2 & $\#$ \\
\hline Pistacia atlantica & - & - & - & - & 1.0 & 0.2 & 4.8 & 3.4 & 0.5 & \# \\
\hline \multicolumn{11}{|l|}{ Dry fruits } \\
\hline Rumex lunaria & 1.0 & 0.1 & 1.5 & 0.1 & 3.5 & 1.4 & - & - & 1.9 & 0.3 \\
\hline $\begin{array}{l}\text { Bituminaria } \\
\quad \text { bituminosum }\end{array}$ & - & - & 3.0 & 0.4 & 2.5 & 0.4 & 4.8 & 3.4 & 1.9 & 0.2 \\
\hline Chenopodium sp. & 0.5 & \# & - & - & - & - & - & - & 0.2 & \# \\
\hline $\begin{array}{l}\text { Medicago } \\
\quad \text { polimorpha }\end{array}$ & - & - & - & - & 0.5 & 0.1 & - & - & 0.2 & $\#$ \\
\hline Seeds indet. & 7.0 & 1.7 & 4.5 & 1.9 & 1.0 & 0.3 & 4.8 & 3.4 & 4.2 & 1.6 \\
\hline Number of seeds & 3,468 & & 3,522 & & 1,183 & & 29 & & 8,202 & \\
\hline \multicolumn{11}{|c|}{ Animal components } \\
\hline Gasteropoda & 10.5 & 2.6 & 1.0 & 0.2 & 4.0 & 0.7 & 19.0 & 4.1 & 5.6 & 1.1 \\
\hline Diplopoda & 17.5 & 4.6 & 10.5 & 2.0 & 32.5 & 6.0 & 19.0 & 4.1 & 20.1 & 4.1 \\
\hline Araneae & 14.0 & 3.7 & 16.0 & 2.8 & 13.0 & 2.4 & 19.0 & 3.3 & 14.5 & 2.9 \\
\hline Acari & 2.5 & 0.6 & 2.5 & 0.4 & 4.0 & 0.7 & - & - & 2.9 & 0.6 \\
\hline Zygentoma & 1.0 & 0.2 & - & - & - & - & - & - & 0.3 & 0.1 \\
\hline Dermaptera & 9.5 & 2.6 & 12.0 & 2.5 & 13.5 & 2.5 & 9.5 & 1.7 & 11.6 & 2.5 \\
\hline Orthoptera & 5.5 & 1.4 & 7.0 & 1.2 & 13.0 & 2.3 & 19.0 & 3.3 & 8.9 & 1.7 \\
\hline Hemiptera & 47.0 & 27.7 & 55.0 & 21.0 & 46.0 & 12.6 & 47.6 & 37.2 & 49.3 & 20.4 \\
\hline Coleoptera & 55.0 & 23.1 & 55.0 & 16.6 & 39.5 & 9.9 & 38.1 & 12.4 & 49.4 & 15.8 \\
\hline Hymenoptera & 54.0 & 17.4 & 36.5 & 11.8 & 23.0 & 4.8 & 19.0 & 3.3 & 37.2 & 10.5 \\
\hline Formicidae & 21.0 & 10.1 & 57.5 & 37.0 & 61.5 & 39.7 & 23.8 & 5.0 & 45.9 & 29.8 \\
\hline Isoptera & - & - & - & - & 12.0 & 13.2 & 14.3 & 21.5 & 4.3 & 5.4 \\
\hline Larva & 3.0 & 0.7 & 2.0 & 0.4 & 4.0 & 0.7 & 9.5 & 1.7 & 3.2 & 0.6 \\
\hline \multicolumn{11}{|l|}{ Lepidoptera } \\
\hline Lepidoptera & - & - & 0.5 & 0.1 & - & - & - & - & 0.2 & $\#$ \\
\hline Diptera & 2.0 & 0.5 & 1.0 & 0.2 & 3.5 & 0.6 & 4.8 & 0.8 & 2.3 & 0.4 \\
\hline Insecta indet. & 14.0 & 4.4 & 17.5 & 3.6 & 14.0 & 2.9 & 4.8 & 0.8 & 14.8 & 3.5 \\
\hline Mus domesticus & 0.5 & 0.1 & 0.5 & 0.1 & - & - & 4.8 & 0.8 & 0.5 & 0.1 \\
\hline Gallotia galloti & 0.5 & 0.1 & 0.5 & 0.1 & 4.0 & 0.7 & - & - & 1.6 & 0.3 \\
\hline $\begin{array}{l}\text { Chalcides } \\
\text { viridanus }\end{array}$ & - & - & - & - & 1.0 & 0.2 & - & - & 0.3 & 0.1 \\
\hline Number of prey items & is 809 & & 1,126 & & 1,107 & & 121 & & 3,163 & \\
\hline $\mathrm{r}^{2}-\mathrm{s}$ & 0.97 & & 0.97 & & 0.96 & & 0.90 & & 0.96 & \\
\hline
\end{tabular}




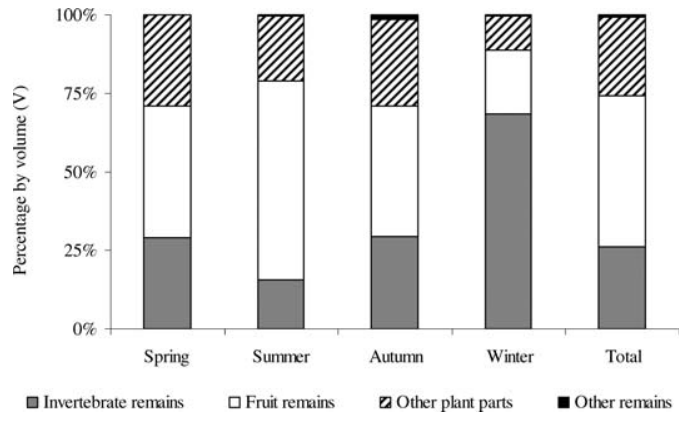

FIG. 1. Volume percentage for each group items consumed by Gallotia galloti in El Pleito (Tenerife, Canary Islands) in different seasons. "Other remains" include vertebrate remains, soil and stones.

of these three variables (Angular transformed, ANCOVA: $F_{3,607}=39.63, P<0.001 ; F_{3,607}=$ 36.20, $P<0.001 ; F_{3,607}=46.90, P<0.001$; respectively).

Mean number of seeds per fecal pellet varied seasonally $\left(\chi_{3}^{2}=59.84, P<0.001\right)$; after subsequent $U$-tests, three homogeneous groups were detected: summer/spring to autumn to winter. The highest value was recorded in one fecal pellet collected in summer $(N=264$ seeds; 260 of $C$. canariensis, three of $R$. crenulata and one of Ficus carica). The number of fleshy-fruited plant species in fecal pellets varied significantly among seasons $\left(\chi_{3}^{2}=71.10, P<0.001\right.$; subsequent $U$-tests, $P<0.012)$, ranging from two in winter to five in summer and autumn, respectively (Table 3).

The main animal prey types varied significantly among seasons, except Aranea, Dermaptera, and Orthoptera $\left(G_{3}=2.67 ; G_{3}=0.43 ; G_{3}=\right.$ $6.08, P>0.05$, respectively). Ants were more abundant in fecal pellets during summer and autumn $\left(G_{3}=306.15, P<0.001\right)$ and Hemiptera, Coleoptera, and Hymenoptera in spring $\left(G_{3}=89.77, P<0.001 ; G_{3}=63.10, P<0.001 ; G_{3}\right.$ $=93.26, P<0.001)$. No statistical differences were detected in the mean number of invertebrate groups (those detailed in Table 2) in pellets throughout the seasons $\left(\chi_{3}^{2}=3.87, P=\right.$ 0.27; Table 3).

The high positive correlations between FO and $\% \mathrm{~N}$ of particular items, which were statistically significant, indicate that those components consumed frequently also tend to make up the highest amount in diet (Table 2).

The Morisita index indicated a high trophic overlap between summer and autumn (0.87) The lowest trophic overlap was detected between spring and autumn (0.23). The rest of the comparisons reached values nearest to 0.5 . Levin's niche breadth index was broader in summer and narrower in spring; in the other two seasons this index showed intermediate values (Table 3).

Spatial Variation of Fleshy Fruit Consumption.The consumption of fruits $(\mathrm{V})$ varied in different subtransects $\left(\chi_{9}^{2}=23.16, P=0.006\right)$, as did the plant material volume $\left(\chi_{9}^{2}=20.71, P=0.014\right)$. Significant differences were detected in the seed number of the different fleshy-fruited plants that occurred in fecal pellets from each subtransect $\left(G_{135}=4751.92, P<0.001\right)$. In general, we detected a higher number of fleshy-fruited plant species in lizard pellets in those subtransects in which those plants were present. Significant correlations between plant cover $(\%)$ and their respective consumption (\%FO) were detected for the following species: $J$. odoratissimum $\left(r_{s}=0.81 ; P=0.004\right)$, Rubia fruticosa $\left(r_{s}=0.73 ; P=0.016\right), R$. crenulata $\left(r_{s}\right.$ $=0.67 ; P=0.033)$, and Ruta pinnata $\left(r_{s}=0.70 ; P\right.$

TABLE 3. Characteristic of droppings and diet of Gallotia galloti throughout the study year (March 2005 through February 2006) in El Pleito (Tenerife, Canary Islands).

\begin{tabular}{|c|c|c|c|c|c|}
\hline & Spring & Summer & Autumn & Winter & Total \\
\hline Mean dropping diameter \pm SD & $6.64 \pm 1.52$ & $7.02 \pm 1.31$ & $6.23 \pm 1.48$ & $4.26 \pm 1.30$ & $6.55 \pm 1.53$ \\
\hline $\begin{array}{l}\text { Mean fruit species / } \\
\text { dropping } \pm S D\end{array}$ & $1.39 \pm 0.88$ & $2.20 \pm 1.14$ & $1.64 \pm 0.97$ & $0.86 \pm 0.79$ & $1.71 \pm 1.06$ \\
\hline $\begin{array}{l}\text { Mean invertebrate taxa/ } \\
\text { dropping } \pm \text { SD }\end{array}$ & $2.57 \pm 1.23$ & $2.74 \pm 1.26$ & $2.84 \pm 1.41$ & $2.48 \pm 1.25$ & $2.71 \pm 1.30$ \\
\hline Mean seed/dropping \pm SD & $17.34 \pm 33.99$ & $17.61 \pm 33.65$ & $5.92 \pm 7.08$ & $1.38 \pm 1.69$ & $13.21 \pm 27.24$ \\
\hline$\%(\mathrm{~V})$ plant material $\pm \mathrm{SD}$ & $70.3 \pm 23.0$ & $83.4 \pm 14.6$ & $67.9 \pm 24.9$ & $30 \pm 32.3$ & $72.4 \pm 24.1$ \\
\hline No. fleshy fruit species/season & 15 & 16 & 15 & 8 & 20 \\
\hline $\begin{array}{l}\text { No. invertebrate categories / } \\
\text { season }\end{array}$ & 13 & 13 & 13 & 12 & 15 \\
\hline \multicolumn{6}{|l|}{ \% droppings with: } \\
\hline plant material & 98 & 100 & 98.5 & 76.2 & 98.1 \\
\hline plant material (excluding fruits) & 73 & 71.5 & 71 & 23.8 & 70.2 \\
\hline fruit remains & 88 & 98.5 & 92 & 61.9 & 91.8 \\
\hline invertebrates & 98 & 99.5 & 96.5 & 90.5 & 97.7 \\
\hline Levin's niche-breadth index & 0.109 & 0.270 & 0.226 & 0.243 & 0.232 \\
\hline
\end{tabular}




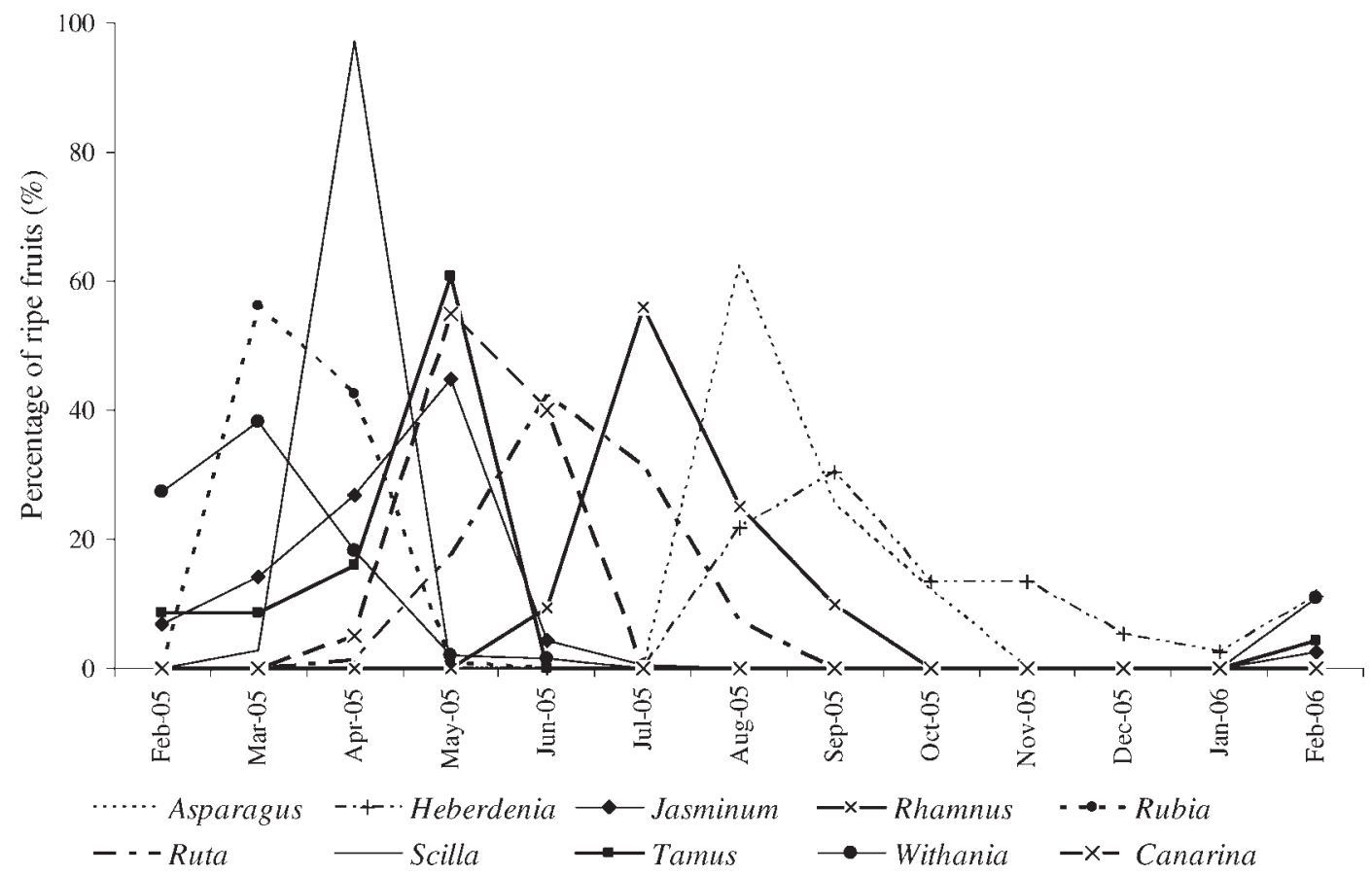

FIG. 2. Availability of ripe fruits (\% of the crop size) during a year (February 2005 to February 2006) in El Pleito (Tenerife, Canary Islands).

$=0.024)$. On a microspatial scale in subtransects, a high concordance was recorded between the consumption of fleshy-fruited plant species and their respective availability in the case of those plants of greater abundance and cover (Table 1, Fig. 3).

\section{DISCUSSION}

Diet.-Our results indicate that the diet of G. gallot $i$ is composed of a large proportion of plant components on an annual basis, as reported in other populations (Valido et al., 2003; Roca et al., 2005; and references therein) and other Gallotia species (Pérez-Mellado et al., 1999; Valido and Nogales, 2003; Martín et al., 2005; and references therein). The importance of plant material in the diet of Gallotia spp. contrasts with the diet of the majority of lacertids (see Van Damme, 1999), being the most herbivorous group within Lacertidae (Carretero, 2004).

Seasonal variation in diet was associated with changes in the availability of fleshy fruits (Fig. 2) and presumably some invertebrates (AR and MN pers. obs.). Larger amounts of plant material, mainly fruits $(63 \%$ of $\mathrm{V})$, and high numbers of ants were ingested through the summer (dry period). This pattern is characteristic of lacertid diets in Mediterranean island ecosystems because of limited food availability during droughts (Pérez-Mellado and Corti,
1993; Perera et al., 2006; see also Carretero, 2004). During the dry period (summer), fleshy fruits supply an important amount of water (Pérez-Mellado et al., 1999). High consumption of fruits could be related to the dry conditions of this habitat during this season and the high water content of fruits (Jordano, 2000), as well as the overall availability of ripe fruits and maybe a decrease in invertebrate abundance as well (Cooper and Vitt, 2002; Olesen and Valido, 2003).

Valido et al. (2003) reported the frequent consumption of fleshy fruits by G. galloti throughout the year, reaching minimum values $(\mathrm{FO}<30 \%)$ in the period December to February; a similar pattern was detected in our study. However, the highest values of FO were reached in summer, whereas in coastal scrublands, it was recorded in spring (Valido et al., 2003). The higher aridity, temperature, and sunny conditions in the latter habitat contributed to the early ripening of fruits. Furthermore, a high $\mathrm{FO}$ for the entire year was found (91.8\%; Table 3) compared to coastal environments. Clear evidence of this is the fact that the number of seeds in the thermophilous scrubland was 3.1 times higher than in the xeric coastal habitat. Furthermore, we found 16 fleshy-fruited plant species in fecal pellets; this number is the highest known for lacertids in a particular habitat. 
Jasminum odoratissimum

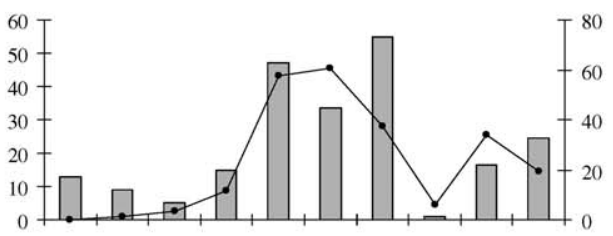

Opuntia maxima

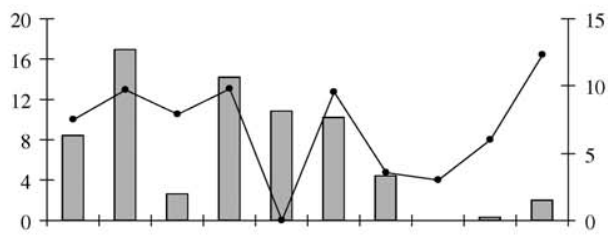

Rhamnus crenulata

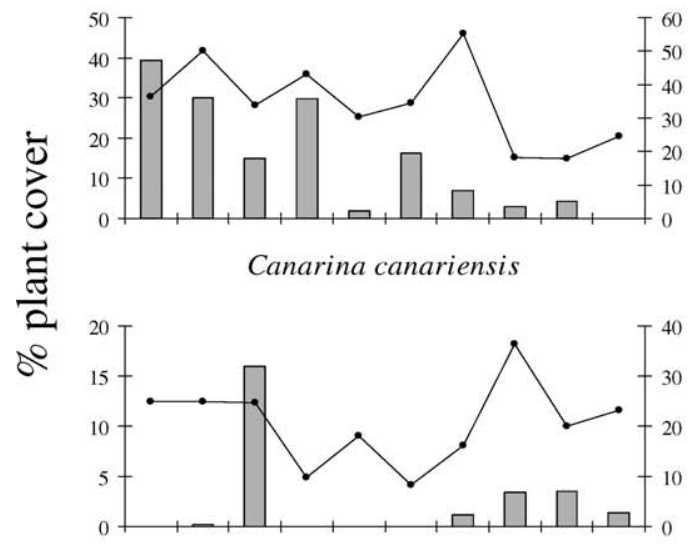

Asparagus plocamoides

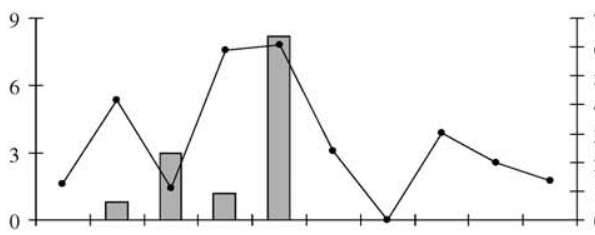

Bosea yervamora

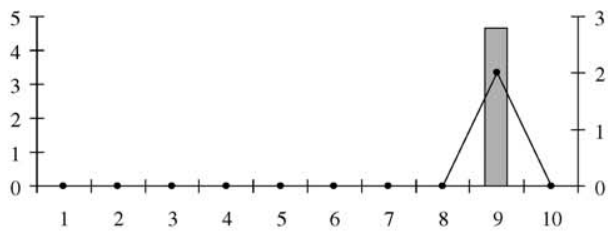

Sub-transects
Rubia fruticosa

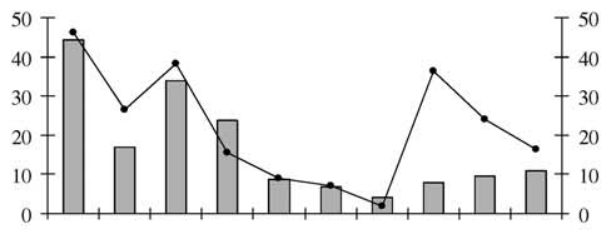

Heberdenia excelsa

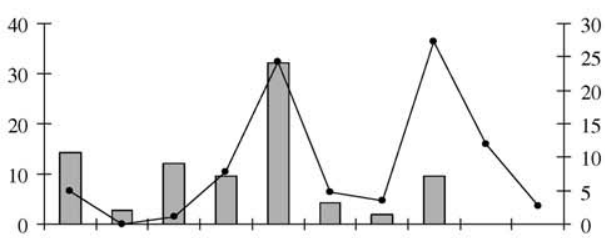

Rubus ulmifolius

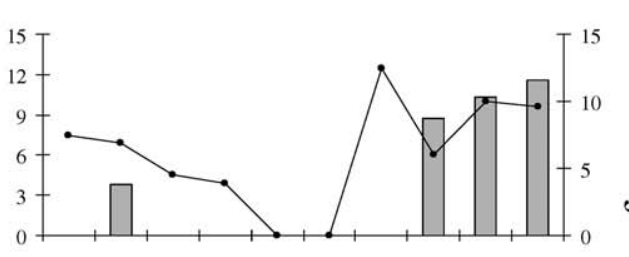

Tamus edulis

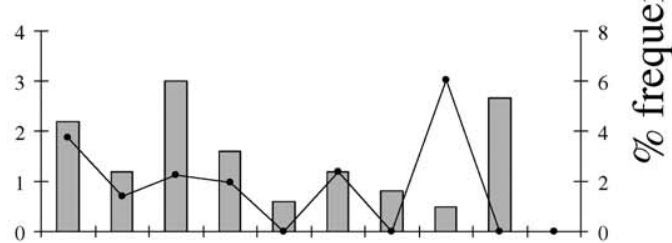

Withania aristata

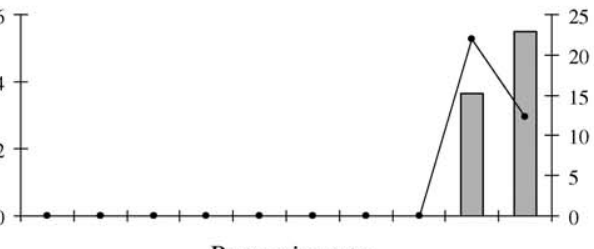

Ruta pinnata

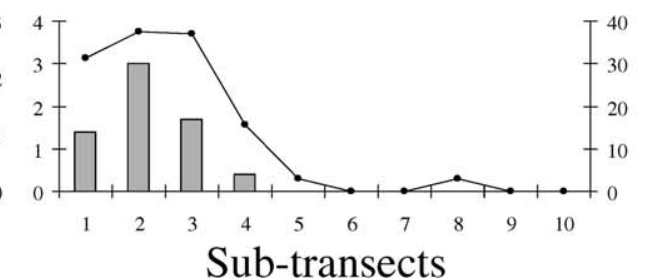

Sub-transects

FIG. 3. Consumption of fleshy fruits in percent of frequency of occurrence (line and dots) and percent of plant cover (bars) in subtransects by Gallotia galloti in El Pleito (Tenerife, Canary Islands). 
Based on the positive relationship between pellet diameter and lizard size (Valido and Nogales, 2003), we deduced that smaller lizards were more active than larger ones in cold periods; and larger lizards were more herbivorous and frugivorous than smaller ones. The latter suggests an ontogenetic change in diet such as has been reported for other lizards (Pough, 1973; Sadek, 1981; Duffield and Bull, 1998).

In lacertids, plant consumption varies intraspecifically among seasons and populations (Cooper and Vitt, 2002; Perera et al., 2006). In the case of G. galloti, this has been reported among seasons (Valido et al., 2003) and populations (Valido and Nogales, 2003). However, it has not been studied previously at a microspatial scale. Our results showed differences in the consumption of fruits and plant material between subtransects, indicating that the frugivorous and herbivorous diet of lizards to vary on a variety of spatial and temporal scales. Thus, this behavior seems to vary on all scales.

Consumption of invertebrate taxa varied between seasons as well. Some groups were consumed intensively when their own demographic explosions took place (i.e., Formicidae in summer and early autumn, Hymenoptera in spring, and gastropods in winter and spring; $\mathrm{AR}$ and MN, pers. obs.). Consumed animal components were more diverse in the Canarian thermophilous scrublands than in the coastal scrublands (17 phylogenetic categories of invertebrates vs. nine reported by Valido et al., 2003). In $0.4 \%$ of pellets examined, lizard skin and other lizard body parts were present. Considering that skin fragments were the most abundant lizard body part, with only one occurrence of a pelvis bone, cannibalism is not frequent (Sadek, 1981).

Because mountains block sunlight, the study area was partially in shadow from middle of October through middle of March and totally in shadow from December to January. Only 21 pellets were collected in winter, presumably because of lower temperatures and reduced activity. Eighty-two percent of autumn pellets were collected from September through 24 October because after this date, storms and rains were frequent, and lizards were not active. The trophic overlap observed between summer and autumn seems to be a consequence of this methodological bias. Diets in spring and autumn had least overlap, probably because of the effect of climatic conditions (temperature, rainfall, etc.) of both seasons on fruit and prey availability. The high consumption of $R$. fruti$\cos a$ fruits in spring (45\% of all ingested fruits) resulted in a narrow trophic niche. The most diverse diet, probably the result of scarcity of resources in this season (Pérez-Mellado et al., 1999), was reported in summer.

Lizards as Seed Dispersers.- Seasonal variation in mean number of seeds and in fleshy-fruited plant species per pellet, suggest variation in the importance of lizards as seed dispersers. In winter, the number of seeds reached minimum values, and lizards were less active (Table 3); therefore endothermic animals (Sylviidae, Turdidae and the endemic pigeon Columba junoniae) would be more important as seed dispersers for winter-fruiting plants, such as $R$. crenulata, $H$. excelsa, or Asparagus plocamoides.

It is possible that we underestimated plants with small canopies (e.g., C. canariensis, Tamus edulis, or $A$. plocamoides) because our linear transects were widely distributed (every $10 \mathrm{~m}$ of the original transect, see Materials and Methods). However, we found that seeds from locally distributed fleshy-fruited plant species only appeared in pellets collected in those same subtransects. Therefore, our data indicate that G. galloti acts as a seed disperser on a small spatial scale related to its home range (57.8 \pm $27.4 \mathrm{~m}^{2}$; Molina-Borja, 1985).

Because of the high density of lizards in the open environments of Tenerife (Molina-Borja, 1991; Valido, 1999), and the large number of seeds removed, as well as their high germination percentage (A. Rodríguez et al., unpubl. data), the role of lizards can be very important in the seed dispersal system of many fleshyfruited plant species (Valido, 1999). This ecological role has also been demonstrated in other plants and lizards species (Varela and Bucher, 2002; Wotton, 2002; Godínez-Álvarez, 2004; and reference therein). In contrast, in continental Mediterranean scrublands, the main seed dispersers are passerine birds (Turdidae, Sylviidae, and Muscicapidae), followed in importance by some carnivores (Herrera, 2001). However, the Canarian themophilous scrublands support fewer frugivorous birds, and native carnivores are absent in these islands.

Acknowledgments.-We are grateful to many friends for helping us during the fieldwork but especially to Rut Martínez. We would like to thank R. Gutiérrez for technical support. H. López, A. Pérez, and D. P. Padilla contributed during arthropod identification. M. A. Carretero, A. Valido, three anonymous reviewers, the Associate Editor (R. Burke), and the Editor (G. R. Smith) provided useful comments and suggestions to improve this manuscript. This work was partially financed by a Canarian Government project (PI042004/037) and supported by Feder funds from the European Union. AR benefited from a postgraduate 
fellowship (I3P-BPG2005) from the Spanish National Research Council.

\section{Literature Cited}

Ancochea, E., J. M. Fuster, E. Ibarrola, A. Cendrero, J. Coello, F. Hernán, J. M. Cantagrel, and C. Jamona. 1990. Volcanic evolution of the island of Tenerife (Canary Islands) in the light of new K-Ar data. Journal of Volcanology and Geothermal Research 44:231-249.

Bennett, A. F., and G. C. Gorman. 1979. Population density and energetics of lizards on a tropical island. Oecologia 42:339-358.

Carretero, M. A. 2004. From set menu to a la carte. Linking issues in trophic ecology of Mediterranean lacertids. Italian Journal of Zoology (Suppl.) 2:121-133.

COOPER, W. E., AND L. J. VITT. 2002. Distribution, extent, and evolution of plant consumption by lizards. Journal of Zoology 257:487-517.

DíAZ, E. 1980. Notas sobre el lagarto tizón (Lacerta galloti). Doñana Acta Vertebrata 7:5-96.

Duffield, G. A., AND C. M. Bull. 1998. Seasonal and ontogenetic changes in the diet of Australian Skink Egernia stokesii. Herpetologica 54:414-419.

EspinOza, R. E., J. J. Wiens, and C. R. Tracy. 2004. Recurrent evolution of herbivory in small, coldclimate lizards: breaking the ecophysiological rules of reptilian herbivory. Proceeding of the National Academy of Sciences of the USA 101:16819-16824.

Godínez-Álvarez， H. 2004. Pollination and seed dispersal by lizards: a review. Revista Chilena de Historia Natural 77:569-577.

GonZÁlez, M. N., J. Rodrigo, AND C. RodrígueZ. 1986. Flora y Vegetación del Archipiélago Canario. Edirca, Las Palmas de Gran Canaria, Spain.

Gorman, M. L. 1979. Island Ecology Chapman and Hall, London.

Herrel, A., B. VANHOOYDONCK, R. JOAChim, AND D. IRSCHICK. 2004. Frugivory in polychrotid lizards: effects of body size. Oecologia 140:160-168.

Herrera, C. M. 2001. Dispersión de semillas por animales en el Mediterráneo: ecología y evolución. In R. Zamora and F. I. Pugnaire (eds.), Ecosistemas Mediterráneos: Análisis Funcional, pp. 125-152. CSIC and AEET, Granada, Spain.

IzQuierdo, I., J. L. Martín, N. ZuRita, AND M. Arechavaleta. 2004. Lista de Especies Silvestres de Canarias (Hongos, Plantas y Animales Terrestres) 2004. Consejería de Medio Ambiente y Ordenación Territorial. Gobierno de Canarias, Santa Cruz de Tenerife, Spain.

JANZEN, D. H. 1973. Sweep samples of tropical foliage insects: effects of seasons, vegetation types, elevation, time of day, and insularity. Ecology 54:678-708.

JoRDANO, P. 2000. Fruits and frugivory. In M. Fenner (ed.), Seeds, the Ecology of Regeneration in Plant Communities, pp. 125-165. Commonwealth Agricultural Bureau International, Wallingford, U.K.

KREBS, C. J. 1999. Ecological Methodology. Benajmin/ Cummings Series. Addison Wesley Longman, CA.
Martín, J. E., G. A. Llorente, V. Roca, M. A. Carretero, A. Montori, X. Santos, and R. Romeo. 2005. Relationship between diet and helminths in Gallotia caesaris (Sauria: Lacertidae). Zoology 108:121-130.

Marzol, V. 2000. El clima. In G. Morales and R. Péres (eds.), Gran Atlas Temático de Canarias, pp. 87-106. Editorial Interinsular Canaria, Santa Cruz de Tenerife, Spain.

Molina-BorJA, M. 1985. Spatial and temporal behaviour of Gallotia galloti in a natural population of Tenerife. Bonner Zoologische Beiträge 36:541-552.

- 1991. Notes on alimentary habits and spatialtempora distribution of eating behaviour patterns in a natural population of lizards (Gallotia galloti). Vieraea 20:1-9.

Nogales, M., E. C. Hernández, and F. Valdés. 1999. Seed dispersal by commom ravens Corvus corax among island habitats (Canarian Archipelago). Écoscience 6:56-61.

Olesen, J. M., And A. Valido. 2003. Lizards as pollinators and seeds dispersers: an island phenomenon. Trends in Ecology and Evolution 18:177-181.

Perera, A., V. Pérez-Mellado, M. A. Carretero, and D. J. HARRIS. 2006. Variation between populations in the diet of the Mediterranean Lizard Lacerta perspicillata. Herpetological Journal 16:107-113.

Pérez-Mellado, V., and C. Corti. 1993. Dietary adaptations and herbivory in lacertid lizards of the genus Podarcis from western Mediterranean islands (Reptilia: Sauria). Bonner Zoologische Beiträge 44:193-220.

Pérez-Mellado, V., M. Romero-Beviá, F. Ortega, S. Martín-García, A. Perera, M. López-Vicente, and C. Galache. 1999. El uso de los recursos tróficos en Gallotia simonyi (Sauria, Lacertidae) de la isla de El Hierro (Islas Canarias). In L. F. López-Jurado and J. A. Mateo (eds.), El Lagarto Gigante de El Hierro. Bases para su Conservación, pp. 63-83. Asociación Herpetológica Española. Monografías de Herpetología no. 4, Las Palmas de Gran Canaria, Spain.

Pough, H. 1973. Lizard energetics and diet. Ecology 54:837-844.

Roca, V., M. A. Carretero, G. A. Llorente, A. Montori, and J. E. Martín. 2005. Helminth communities of two lizard populations (Lacertidae) from Canary Islands (Spain): host diet-parasite relationships. Amphibia-Reptilia 26:535-542.

Rodda, G. H., and K. Dean-Bradley. 2002. Excess density compensation of island herpetofaunal assemblages. Journal of Biogeography 29:623-632.

SADEK, R. A. 1981. The diet of the Madeiran Lizard Lacerta dugesii. Zoological Journal of the Linnean Society 73:313-341.

SAntos, A. 2000. La vegetación. In G. Morales and R. Péres (eds.), Gran Atlas Temático de Canarias, pp. 121-146. Editorial Interinsular Canaria, Santa Cruz de Tenerife, Spain.

Schoener, T. W., AND A. Schoener. 1980. Densities, sex ratios and population structure in four species of Bahamian Anolis lizards. Journal of Animal Ecology 49:19-53.

SокоL, O. M. 1967. Herbivory in lizards. Evolution 21:192-194. 
Sunding, P. 1979. Origins of the Macaronesian Flora. In D. Bramwell (ed.), Plants and Islands, pp. 13-40. Academy Press, London.

SZARSKI, H. 1962. Some remarks on herbivorous lizards. Evolution 16:529.

VALIDO, A. 1999. Ecología de la dispersión de semillas por los lagartos endémicos canarios (g. Gallotia, Lacertidae). Unpubl. Ph.D. diss., University of La Laguna, Tenerife, Canary Islands, Spain.

Valido, A., AND M. Nogales. 1994. Frugivory and seed dispersal by the lizard Gallotia galloti (Lacertidae) in a xeric habitat of the Canary Islands. Oikos 70:403-411.

2003. Digestive ecology of two omnivorous Canarian lizards species (Gallotia, Lacertidae). Amphibia-Reptilia 24:331-344.

Valido, A., M. Nogales, and F. M. Medina. 2003. Fleshy fruits in the diet of Canarian Lizards Gallotia galloti (Lacertidae) in a zeric habitat of the island of Tenerife. Journal of Herpetology 37:741-747.

VAN DAMME, R. 1999. Evolution of herbivory in lacertid lizards: effects of insularity and body size. Journal of Herpetology 33:663-674.

Varela, R. O., AND E. H. Bucher. 2002. The lizard Teius teyou (Squamata: Teiidae) as a legitimate seed disperser in the dry Chaco forest of Argentina. Studies on Neotropical Fauna and Environment 37:115-117.

VITT, L. J. 2004. Shifting paradigms: herbivory and body size in lizards. Proceedings of the National Academy of Sciences of the USA 101:16713-16714.

WotTon, D. M. 2002. Effectiveness of the Common Gecko (Hoplodactylus maculatus) as a seed disperser on Mana Island, New Zealand. New Zealand Journal of Botany 40:639-647.

Accepted: 14 October 2007. 